\title{
Fragility Functions for a Reinforced Concrete Structure Subjected to Earthquake and Tsunami in Sequence
}

\author{
Crescenzo Petrone ${ }^{1}$, Tiziana Rossetto ${ }^{2}$, Marco Baiguera ${ }^{2}$, Camilo De la Barra \\ Bustamante $^{2}$ and Ioanna Ioannou ${ }^{2}$
}

\section{ABSTRACT}

Many coastal regions lying on subduction zones are likely to experience the catastrophic effects of cascading earthquake and tsunami observed in recent events, e.g., 2011 Tohoku Earthquake and Tsunami. The influence of earthquake on the response of the structure to tsunami is difficult to quantify through damage observations from past events, since they only provide information on the combined effects of both perils. Hence, the use of analytical methodologies is fundamental. This paper investigates the response of a reinforced concrete frame subjected to realistic ground motion and tsunami inundation time histories that have been simulated considering a seismic source representative of the M9 2011 Tohoku earthquake event. The structure is analysed via nonlinear time-history analyses under (a) tsunami inundation only and (b) earthquake ground motion and tsunami inundation in sequence. Comparison of these analyses shows that there is a small impact of the preceding earthquake ground shaking on the tsunami fragility. The fragility curves constructed for the cascading hazards show less than $15 \%$ reduction in the median estimate of tsunami capacity compared to the fragility functions for tsunami only. This outcome reflects the fundamentally different response of the structure to the two perils: while the ground motion response of the structure is governed by its strength, ductility and stiffness, the tsunami performance of the structure is dominated by its strength. It is found that the ground shaking influences the tsunami displacement response of the considered structure due to the stiffness degradation induced in the ground motion cyclic response, but this effect decreases with increasing tsunami force.

Keywords: sequential earthquake-tsunami; cascading earthquake hazard; tsunami engineering; fragility curve; time-history analysis.

\footnotetext{
${ }^{1}$ Willis Towers Watson, London, UK

${ }^{2}$ Department of Civil Environmental \& Geomatic Engineering, University College London, London, UK
} 


\section{INTRODUCTION}

Tsunami have contributed to 250,125 deaths between 1994 and 2013 [1]. They are the deadliest natural hazard, with an average of 79 deaths for every 1,000 people affected, compared to four deaths per 1,000 for other natural hazards. Past tsunami have caused widespread damage and economic losses, with a direct loss of US $\$ 211$ billion being estimated for the 2011 Tohoku event alone [2]. Exposure to this hazard is high, as 6 out of the 10 most populous megacities are at risk of being severely affected by storm surge and tsunami [3]. Moreover, regions at highest risk lie on subduction zones around the Pacific "Ring of Fire" (e.g., Japan, Indonesia, Pacific Northwest), and hence are likely to experience strong ground shaking as well as tsunami inundation [4].

An important component in the evaluation of tsunami impact or risk is the estimation of building response due to tsunami onshore flow. To date the majority of research on this topic has focussed on the development of fragility functions based on post-tsunami damage observed at a given location, so-called "empirical fragility functions", e.g. Suppasri et al. [5] among many others. Empirical tsunami fragility functions are by their nature specific to the event represented in the post-event damage data as well as the local building stock, and are limited by the typical absence of locally recorded tsunami intensity measures, such as the flow velocity. They commonly adopt building damage observations from locations that have been affected by both earthquake and tsunami hazards, implicitly including the response of buildings to the combined hazards. Assessment of structural performance through numerical analyses is therefore essential to overcome these limitations. Analytical fragility functions are therefore needed to complement empirical assessments for a physical understanding of structural behaviour under cascading earthquake and tsunami.

Research on the development of analytical fragility functions for structures subjected to tsunami is growing worldwide. However, compared to analogous studies in earthquake engineering, to date there are only very few published tsunami fragility studies (e.g. Macabuag et al. [6], Nanayakkara and Dias [7], Attary et al. [8], Petrone et al. [9], Alam et al. [10], amongst others). Many of these studies investigated the response of structures located in areas that could be subjected to severe ground shaking before tsunami inundation. The question then arises as to whether the preceding ground motion has an impact on the subsequent tsunami performance of the structure. 
Numerical investigations on structural models are therefore required to investigate the performance of structures under sequential earthquake and tsunami. Structural analysis can be performed by means of numerical models that are able to represent, with varying computational complexity, the response of the structures under ground motion and tsunami in cascade. For instance, Park et al. [11] developed an approach to evaluate the performance of a structure, idealised with a simplified single degree of freedom, under ground motion and tsunami in sequence. Static analysis is performed considering an equivalent tsunami force according to design prescriptions. Rossetto et al. [12] present a comprehensive comparison of several numerical analyses for a tsunami vertical evacuation building. They presented different analysis typologies that can be used to assess the response of a structure and evaluated the bias associated to each approach in predicting the structural response. They found that excellent prediction can be obtained using a seismic nonlinear response history analysis for the ground shaking followed by a transient free vibration and tsunami pushover. Attary et al. [13] have employed such an approach for the loss assessment of a steel building. However, this study only considers global failure mechanisms under the sequential loads, with local damage mechanisms not being accounted for in either the structure modelling or assessment. Such mechanisms have been seen to dominate the collapse of some buildings subjected to tsunami loading $[9,10]$. In the context of coastal infrastructure, Carey et al. [14] have recently applied similar approaches to quantify sequential earthquake and tsunami-induced damage to bridges. They found that there is a reduction in the bridge system to tsunami loading due to residual effects of the preceding earthquake loading. There is a clear gap in knowledge in quantifying the influence of the preceding ground motion on the performance of structures under tsunami actions using realistic ground motions and tsunami inundation time histories on a structural model.

Hence, this study builds on the paper by Rossetto et al. [12], and aims to assess the impact of the preceding ground motion on the tsunami response and fragility of structures. A reinforced concrete structure designed to the Japanese Seismic Codes is subjected to consistent ground motion and tsunami loads, i.e. generated by the same seismic source. An extensive set of ground motion and tsunami "pairs" are simulated for the 2011 M9 Tohoku earthquake event according to the methodology developed by Goda et al. [15]. The structure is analysed via nonlinear response-history analyses under earthquake ground motion and tsunami inundation in sequence to assess the impact of the preceding ground motion on the tsunami response and fragility curve. Finally, an earthquake-tsunami fragility surface is developed for the 
investigated structure to fully quantify the uncertainty in the response due to the tsunami load and ground motion. It should be noted that, while other sources of uncertainty, e.g. material and geometry, are not considered herein, this study is specific to the case-study application and should not adopted for the assessment of buildings designed and constructed in different regions of the world.

\section{CASE-STUDY APPLICATION}

\subsection{STRUCTURAL MODEL}

\subsubsection{Case-study building description}

The building considered in this study is a five-storey reinforced concrete (RC) moment resisting frame (Figure 1). This building was selected from "Structural Design and Member Sections Case Studies" [16], which examines the design of prototypical RC structures to the Japanese Seismic Codes [17,18]. The building is $16.58 \mathrm{~m}$ high, $39.95 \mathrm{~m}$ long and $11.35 \mathrm{~m}$ wide.

In this study, the tsunami is assumed to impact the structure along the y-axis. The lateral loading is therefore resisted by eight two-bay moment resisting frames. Due to the structural regularity in plan and height, one of the intermediate frames X3 (see Figure 1a) is considered for this assessment. Beam cross-section dimensions vary from $45 \times 65 \mathrm{~cm}$ in the first four storeys to $60 \times 70 \mathrm{~cm}$ in the top storey, and all beams are designed with $13-\mathrm{mm}$ diameter with stirrups spacing of $200 \mathrm{~mm}$. The concrete cover is $5 \mathrm{~cm}$ throughout. Beam steel reinforcement ratios vary from $0.87 \%$ at the first storey to $1.0 \%$ at the fifth storey. The columns have larger steel reinforcing ratios, varying from $1.40 \%$ at the first storey to $1.27 \%$ in the upper storeys. The horizontal reinforcement spacing is constant throughout the height of all the columns, without an increase in shear reinforcement ratio at column ends. 


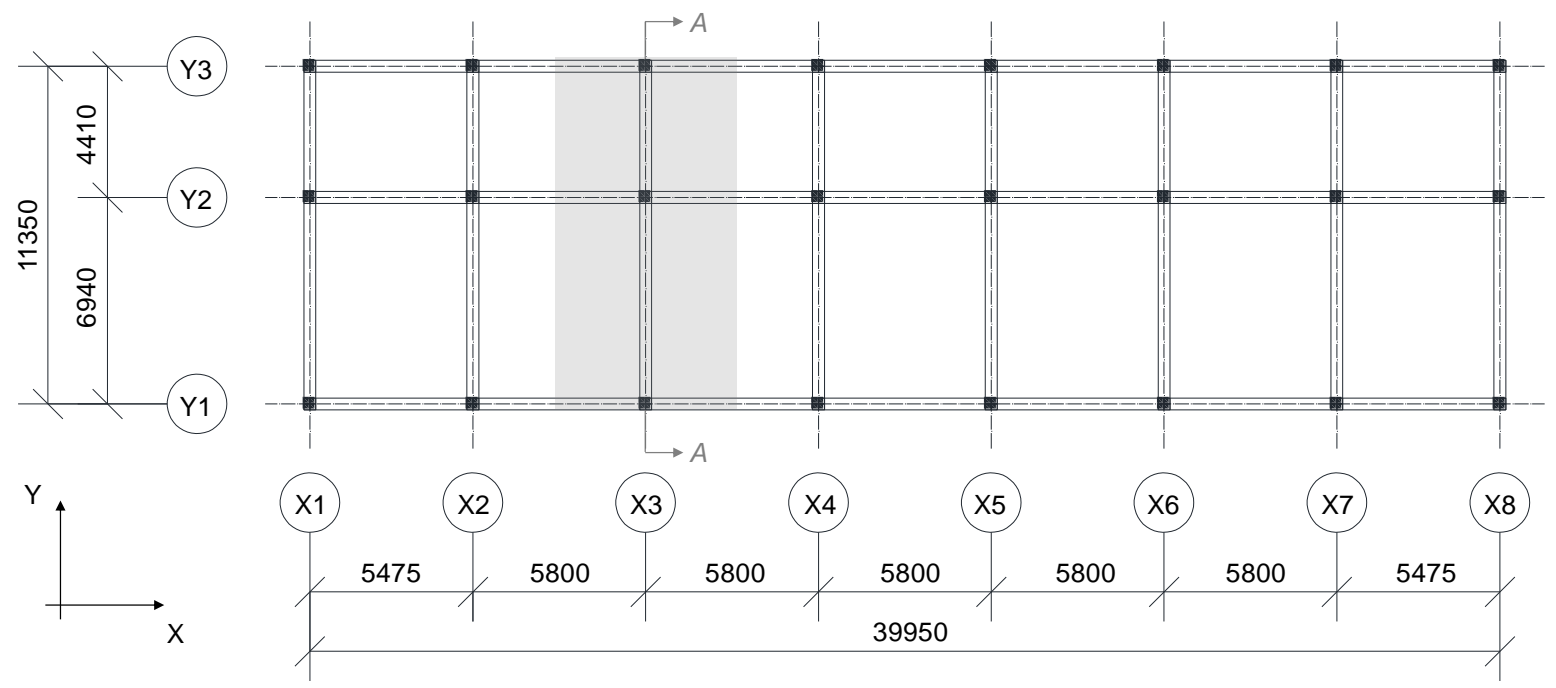

(a)

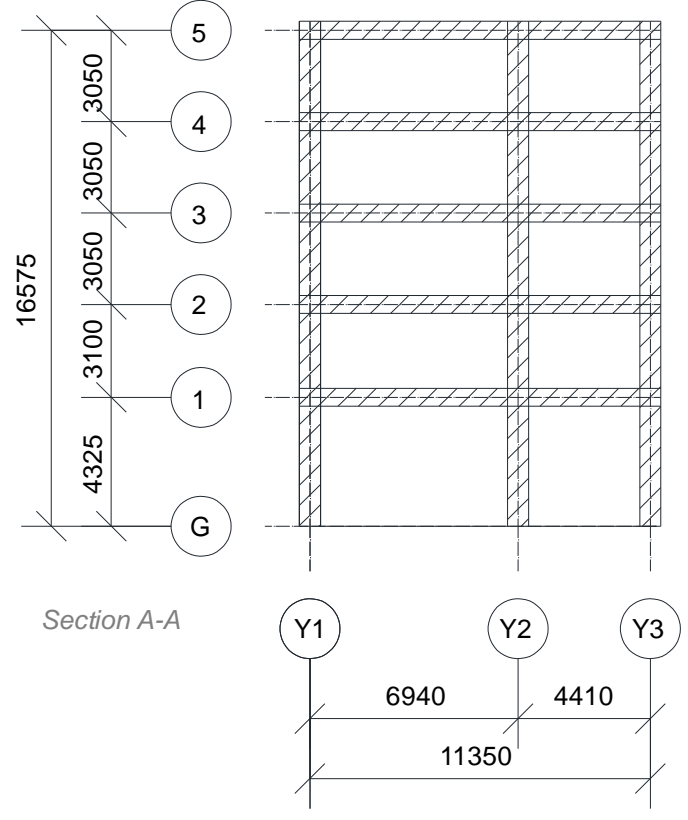

(b)

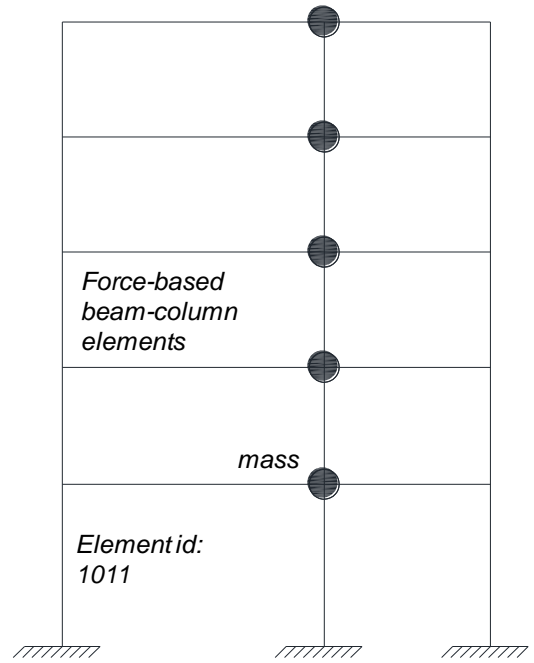

(c)

Figure 1. Case-study building; (a) plan view; (b) elevation view of frame X3 (section A-A); and (c) finite element model of frame X3. (All dimensions are in $\mathrm{mm}$ ).

\section{$116 \quad$ 2.1.2. Finite element model}

117 The case-study structure is modelled using the OpenSees software [19]. A distributed

118 plasticity approach is adopted to model both columns and beams. Force-based nonlinear

119 elements with five Gauss-Lobatto integration points are used. The rectangular cross-sections

120 are discretised using a fibre approach. The composite beam-slab behaviour known as T-beam

121 effect is neglected. 
Mean strengths of steel and unconfined concrete are calculated as $321 \mathrm{MPa}$ and 28.7 MPa, assuming a coefficient of variation (COV) of 5\% and 10\%, respectively [20]. The constitutive material Concrete04 in OpenSees [19], based on Uniaxial Popovics material [21] with an unloading and reloading stiffness model according to Karsan-Jirsa [22] and exponential decay

126 for the strength, is employed to model confined and unconfined concrete. It is noted that 127 Concrete04 model simulates stiffness degradation. Due to the low axial forces in the beams, concrete in the corresponding elements is modelled as unconfined. The steel stress-strain constitutive material is modelled using the Giuffre-Menegotto-Pinto model, named as Steel02 in OpenSees. Reinforcing steel is assumed to have a strain hardening of 0.003 , an ultimate steel strain of 0.3 and a ratio between tensile strength and yielding strength of 1.5 . These values are chosen for consistency with the criteria of the Japanese code [20]. It is acknowledged that a strain hardening ratio of 0.003 is low; however, this has little influence on the earthquake response of the structure, as the seismic actions do not lead to high levels of damage in the structural elements. This choice is conservative for the tsunami analysis as higher strain hardening might be more beneficial; nevertheless, the overall response to tsunami is unlikely to be influenced by strain hardening, as discussed in Macabuag [23]. Beam-column joints were modelled by joining concurrent nodes, with elastic elements only and with no rigid links. Shear failure initiation and degradation of columns is not modelled for the case-study structure, based on a sensitivity study that showed that the hysteretic response of columns of the considered structure is not sensitive to shear degradation, as a result of their transverse reinforcement detailing. Geometric nonlinearity such as P-delta effects is considered.

The seismic mass is modelled by applying lumped masses at the central beam-column joint at each storey (Figure 1c). Gravity loads are uniformly applied to beams. The base nodes are fixed to the ground. The fundamental period of the model is $0.49 \mathrm{~s}$, and the first mode is characterised by an $86 \%$ mass participation factor.

\subsection{EARTHQUAKE AND TSUNAMI SIMULATED TIME-HISTORIES}

148 This paper presents an investigation of the response of the case-study building to

149 earthquake and tsunami in sequence, using a large set of ground motion records and tsunami 150 inundation time histories. These records are selected from the study by Goda et al. [15], which 151 simulates several tsunami traces for the 2011 Tohoku tsunami using a consistent stochasticallygenerated earthquake source model. The ground motion time-histories are simulated using the multiple-event stochastic finite-fault method described in Goda et al. [24], while the tsunami 
155

156

157

158

159

160

161

162

163

164

165

166

167

168

169

170

171

172

173

174

175

176

177

178

180

181

182

183

where $C_{D}$ is the drag coefficient, $\rho$ is the sea water density $\left(1.2 \mathrm{t} / \mathrm{m}^{3}\right), \lambda$ is the choking ratio, $g$

nonlinear shallow water equations with run-up [25]. In total, 803 compatible ground motion and tsunami time-histories are available from the work of Goda et al. [24], which correspond to time-histories of ground acceleration, tsunami inundation depth and flow velocity measured at 73 coastal sites in Japan, for 11 different source models of the 2011 Tohoku event. In this paper, tsunami inundation time histories that overtop the structure are discarded, resulting in a set of 672 earthquake-tsunami records. The maximum tsunami inundation velocity is $7 \mathrm{~m} / \mathrm{s}$.

The study aims to investigate the tsunami response of a structure with different levels of initial damage due to the ground motion. The unscaled records were not capable to bring the structure to extensive damage and it was therefore decided to employ two additional sets of 672 earthquake-tsunami records, where the original acceleration time-histories are scaled by a factor of 3 and 5, respectively. It is noted that in the resulting earthquake-tsunami records, indicated as EQ-TS, the tsunami inundation depth and velocity time-histories remain unaltered.

Physically the ground shaking and wave form are not connected past origination. i.e. both seismic waves and tsunami waves are generated by a fault and propagate away from the source. However, the tsunami does not lose energy or transform significantly as it propagates across deep ocean waters [26]. The tsunami waveform and inundation are only transformed near and onshore, respectively, due to interaction with nearshore bathymetry and topography. Instead earthquake ground motions attenuate significantly with distance from the source, and may or may not be amplified by the soil column at the site. Effectively the scaled records represent what the ground shaking would be if the coast of Japan were shifted East towards the source fault. In such a scenario, the same tsunami wave traces can be considered consistent with these scaled ground motions, since their offshore form will be the same and the same approach bathymetry and topography are used.

In this paper, the tsunami action over the building is considered only as a hydrodynamic lateral force. This force, $F_{\mathrm{T}}(t)$, is calculated from the time-histories of tsunami inundation depth, $h(t)$, and velocity, $u(t)$, using the experimentally-validated formulation of Qi et al. [27]. According to this, the net force per unit of width $b$ of a rectangular building subjected to a freesurface channel flow is:

$$
F_{\mathrm{T}}(t) / b=\operatorname{sgn}(u(t))\left\{\begin{array}{cl}
0.5 C_{D} \rho u(t)^{2} h(t) & \text { if } F_{r}<F_{r c} \\
\lambda \rho g^{1 / 3} u(t)^{4 / 3} h(t)^{4 / 3} & \text { if } F_{r} \geq F_{r c}
\end{array}\right.
$$
is the acceleration of gravity, $F r$ is the Froude number $(F r=u / \sqrt{g h})$, and $F r_{\mathrm{c}}$ is the Froude 
185

186

187

188

189

190

191

192

number threshold. When $F r<F r_{\mathrm{c}}$, the steady-state flow regime is subcritical, while it becomes choked if $F r \geq F r_{\mathrm{c}}$. The parameters $C_{D}, \lambda$ and $F r_{\mathrm{c}}$ are dependent on the blocking ratio parameter $b / w$, which corresponds to the ratio between the obstacle and the flume widths. A blocking ratio of 0.6 is used in this study (i.e., $C_{D}=4.7, \lambda=2.0, F r_{\mathrm{c}}=0.32$ ), as it represents the conditions determined in a dense urban environment [9]. It is noted that this formulation assumes that the structure is impermeable. Tsunami loading is applied on the seaward column only, with a tributary width of $b=5.8 \mathrm{~m}$ (refer to Figure 1 and Eq. 1), considering that the structural is impermeable to flow.

Figure 2 illustrates the pseudo-spectral acceleration at the fundamental period of vibration of the case study structure, $S_{\mathrm{a}}\left(T_{1}\right)$, and peak tsunami force, $F_{\mathrm{T}}$, of the 2,016 EQ-TS pairs.

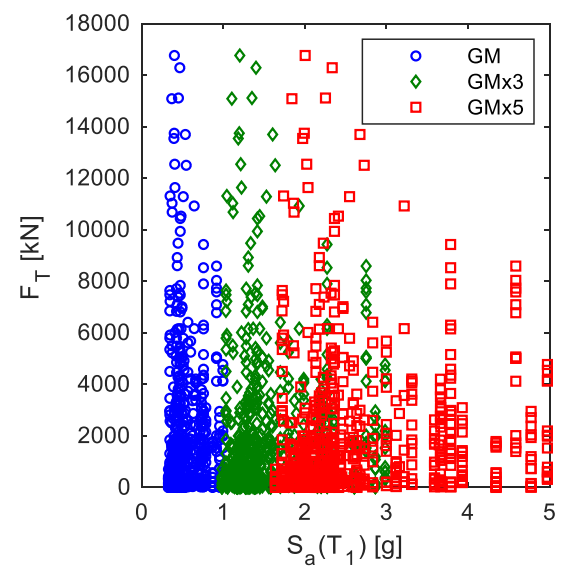

Figure 2. Earthquake-tsunami (EQ-TS) pairs in terms of pseudo-spectral acceleration at the fundamental period of vibration $S_{\mathrm{a}}\left(T_{1}\right)$ of the case study structure $\left(T_{1}=0.49 \mathrm{~s}\right)$ and peak force of the tsunami inundation time history $F_{\mathrm{T}}$. Note: 'GMx3' and 'GMx5' indicate EQ-TS pairs with original ground motion time-histories ('GM') scaled by a factor of 3 and 5.

193

\subsection{NUMERICAL ANALYSIS}

A bespoke methodology is used to analyse the structure under sequential earthquake and tsunami loading. As illustrated in Figure 3, a nonlinear earthquake response history analysis is first performed, where the structural model is subjected to a ground motion record. This is followed by a transient free vibration phase, during which the structure freely oscillates until it stops vibrating. If the structure exhibits a nonlinear response during the ground shaking, this may result in residual deformations, i.e., residual drifts, after the free vibration. The analysis time step for the earthquake phase and for the free-vibration and tsunami phases is $0.01 \mathrm{~s}$ and $0.05 \mathrm{~s}$, respectively (with up to $1 / 50$ reduction factor in particular cases where convergence was difficult to achieve). For the free-vibration phase, analysis duration and structural damping 
203 values are arbitrarily tuned to prevent any further oscillation before the tsunami phase.

204 Newmark integration is used throughout the analysis. In this paper, a 5\% Rayleigh damping 205 ratio is used throughout earthquake and tsunami phases [12], while a fictitious 30\% is applied 206 during the free vibration phase to minimise any vibration in the structure following the ground 207 shaking. The damping matrix for an element or node is specified as a combination of stiffness 208 and mass-proportional damping matrices [19]. Finally, a tsunami inundation response history 209 analysis is carried out as described in [9]. No reduction in the structure weight is considered 210 for the tsunami analyses (i.e. buoyant action is neglected)
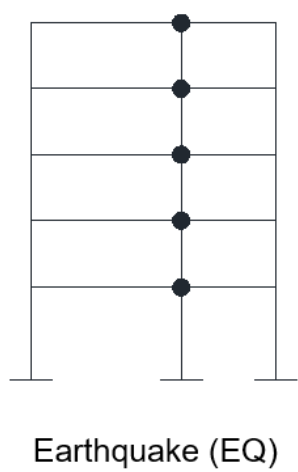

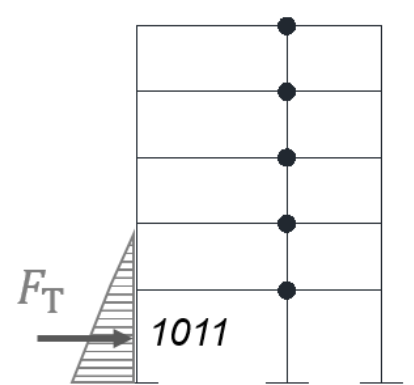

Free Vibration
Tsunami (TS)
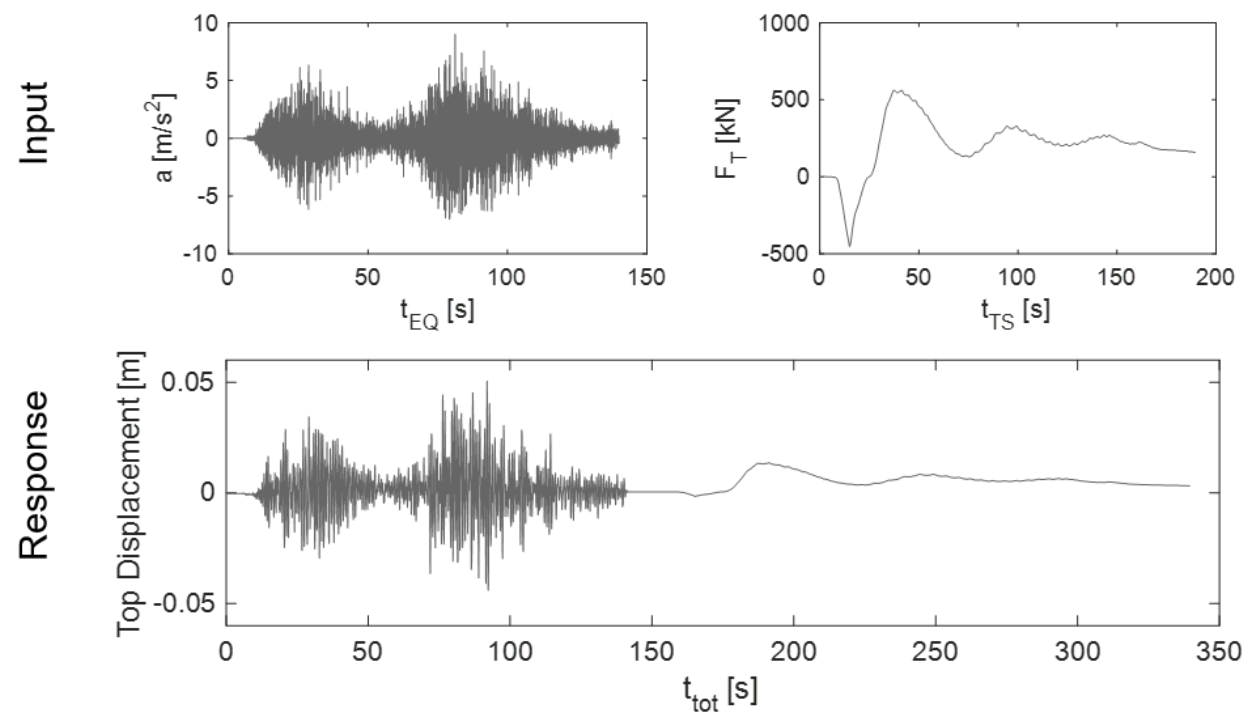

Figure 3. Sequential earthquake and tsunami time-history analysis: conceptual diagram.

\subsection{DAMAGE STATES DEFINITION}

213 The scale of damage states $(d s)$ for the structure subjected to sequential earthquake and

214 tsunami is defined assuming that the engineering demand parameters (EDPs) are not dependent

215 on the type of loading. Five damage states are established to describe the extent of damage 
216 within the structure, from no damage $(d s 0)$ to collapse $(d s 4)$. Good engineering practice 217 supports the definition of damage states that are defined considering damage mechanisms that 218 can form at Section, Member, Storey and Global structural level [28]. These should be defined 219 by threshold values of EDP that define unambiguously the progression between one damage 220 state and the next; with the occurrence of the first of these indicating initiation of the damage 221 state.

The tsunami force $F_{T}$ is assumed to impact one longitudinal side of the structure (i.e., Y1 in Figure 1a). Therefore, the tsunami force acting on each transverse frame is calculated based on the tributary width, i.e., $b=5.8 \mathrm{~m}$ for frame $\mathrm{X} 3$, and is applied to the external columns. Different load patterns (i.e., uniform, triangular, trapezoidal) can be used to apply the load along the columns. Furthermore, different load discretisation can be used, e.g., the force can be applied solely at the storey level [6,7], or at several points along each column within each storey $[8,10]$. Petrone et al. [9] found that applying a triangular or trapezoidal loading pattern, with the load discretised and applied at several locations along the columns within each storey results in a better prediction of both the global and local behaviour of a structure under tsunami loading. In this paper, a triangular force distribution with five force application points per storey is employed.

In this study, due to the number of analyses involved and the study focus on collapse fragility functions, section level EDPs are not adopted, and EDPs at member and global level are also not defined for damage states below collapse. The damage scale adopted is presented in Table 1, and adopts the maximum inter-storey drift ratio (IDR) thresholds proposed in Rossetto et al [28] for a special code RC frame, (i.e., designed according to the modern seismic code) for all damage states. Additionally, seismic pushover analyses and tsunami inundation response history analyses were conducted to validate the defined IDR threshold for $d s 2$ $(0.95 \%)$, and check its correspondence with the occurrence of steel reinforcement yielding in columns. Since Rossetto et al. [28] do not provide an IDR threshold for the slight damage state $(d s 1)$, this study adopts that proposed in HAZUS [29] for special code mid-rise RC frames. For the member-level based collapse definition, it is recognised that due to the large shear forces induced in vertical members by tsunami, column shear failure is possible, even for a seismically designed structure (e.g. as in [9]). Consequently, collapse is also considered to commence when the shear safety factor (SSF), (i.e., the ratio between the maximum internal shear force and the shear strength), is less than 1 in any vertical element. This is reasonable as the duration of 
249 shear failure of a load-bearing element is surpassed [30]. Based on the results of the analysis 250 presented in the next section, column 1011 at the ground floor of the RC frame (see Figure 1c) 251 is the most critical in terms of shear demand under tsunami forces, thus SSF is tracked only in 252 this column. The shear strength of column 1011 is determined using the formulation proposed 253 by Biskinis et al. [31], which also accounts for the level of axial load. At global level, $d s 4$ is 254 defined based on the approach proposed by Petrone et al. [9]. This criterion assumes that partial collapse occurs when the structure is deformed up to a point where the internal force (i.e., net base shear) is reduced by $20 \%$ compared to the applied peak force. The $d s 4$ damage state is assumed to be reached on the first occurrence of any one of the defined member-, storey- or global-level criteria. The final damage state, i.e., following the earthquake and tsunami in sequence, is determined as the maximum value of the damage states attained in each phase of the analysis.

Table 1. Damage scale for earthquake and tsunami in sequence.

\begin{tabular}{cccccc}
\hline $\begin{array}{c}\text { Damage } \\
\text { Type }\end{array}$ & $\begin{array}{c}\text { No Damage } \\
(\boldsymbol{d s 0})\end{array}$ & $\begin{array}{c}\text { Slight Damage } \\
(\boldsymbol{d} \mathbf{s} \mathbf{1})\end{array}$ & $\begin{array}{c}\text { Moderate } \\
\text { Damage }(\boldsymbol{d} \boldsymbol{s})\end{array}$ & $\begin{array}{c}\text { Extensive } \\
\text { Damage }(\boldsymbol{d s})\end{array}$ & Collapse $(\boldsymbol{d} \boldsymbol{s}$ 4) \\
\hline $\begin{array}{c}\text { Member- } \\
\text { level }\end{array}$ & N.A. & N.A. & N.A. & N.A. & $\begin{array}{c}\text { SSF } \geq 1.0 \text { in } \\
\text { column } 1011\end{array}$ \\
$\begin{array}{c}\text { Story-level } \\
\begin{array}{c}\text { Global- } \\
\text { level }\end{array}\end{array}$ & IDR $<0.33 \%$ & IDR $\geq 0.33 \%$ & IDR $\geq 0.95 \%$ & IDR $\geq 2.11 \%$ & IDR $\geq 5.62 \%$ \\
& N.A. & N.A. & N.A. & N.A. & $\begin{array}{c}\text { More than } 20 \% \\
\text { of decay in the } \\
\text { net internal } \\
\text { force. }\end{array}$ \\
\hline
\end{tabular}

\section{RESULTS AND DISCUSSION}

263 Two sets of time-history analyses are performed to simulate the structure response under: (a) tsunami inundation only, (672 analysis); and (b) earthquake shaking and tsunami inundation in sequence (2,016 analysis). This section first compares only the structure's tsunami response phase, which for cases (a) and (b) are denoted as TS and TS $\mathrm{S}_{\mathrm{EQ}-\mathrm{TS}}$, respectively. Then, the final damage resulting from the tsunami only, and the sequential earthquake and tsunami analyses is assessed.

\subsection{IMPACT OF PRECEDING EARTHQUAKE ON TSUNAMI STRUCTURAL} DEMAND

Figure 4 compares the results of the TS $\mathrm{EQ}_{\mathrm{E}-\mathrm{TS}}$ phase from the sequential analysis against the corresponding TS analysis. Figures $4 \mathrm{a}$ and $\mathrm{b}$ plot the IDR values from the two sets of analyses,

273 (i.e., $\mathrm{IDR}_{\mathrm{TS}, \mathrm{EQ}-\mathrm{TS}} / \mathrm{IDR}_{\mathrm{TS}}$, against $S_{\mathrm{a}}\left(T_{1}\right)$ and $F_{\mathrm{T}}$, respectively), for cases where the structure 
reaches $d s 0, d s 1, d s 2$ and $d s 3$, i.e. 1,643 out of 2,016 analyses. The IDR values for $d s 4$ are not plotted as numerical instabilities at collapse initiation do not provide reliable IDR values for

276 the comparison in this section. The results show that, when the structure is subjected to a 277 preceding earthquake, the IDR values obtained under the tsunami inundation are consistently 278 larger. This trend is most noticeable for large $S_{\mathrm{a}}\left(T_{1}\right)$ values and at lower $F_{\mathrm{T}}$ values. The 279 permanent deformation induced by the ground motion is seen to play a key role in the increase 280 IDR during the tsunami. The stiffness reduction during the ground motion phase also augments the maximum displacement during the tsunami phase.

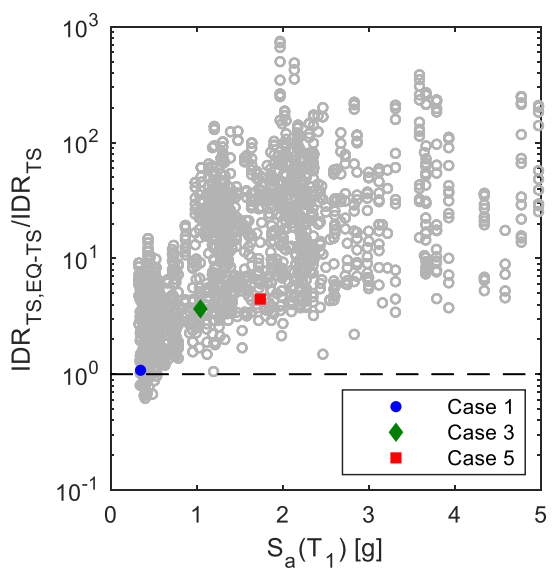

(a)

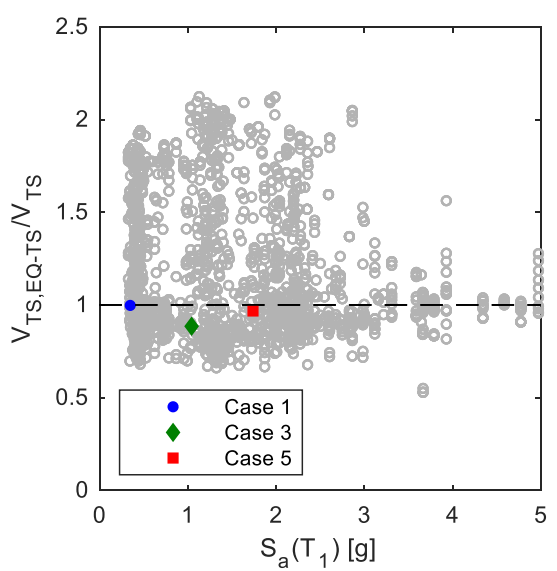

(c)

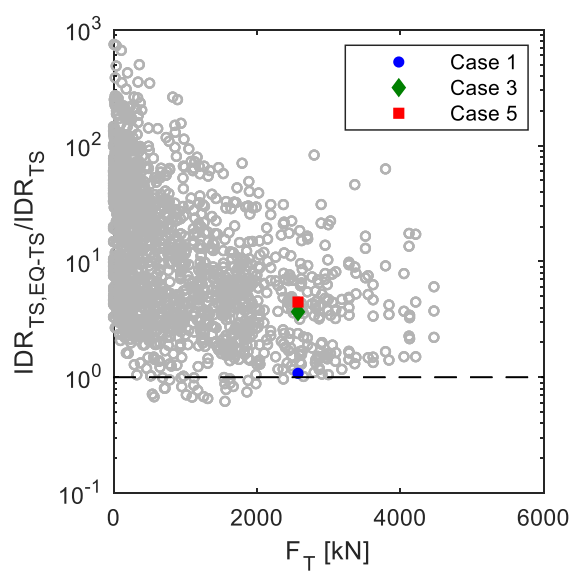

(b)

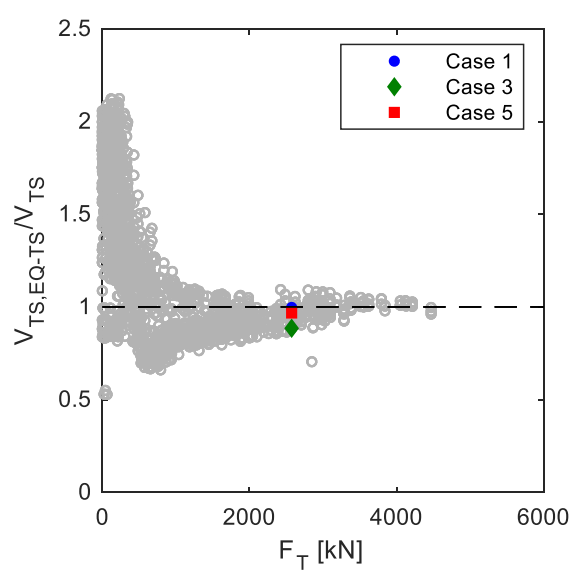

(d)

Figure 4. Comparison between the structure response under the $\mathrm{TS}_{\mathrm{EQ}-\mathrm{TS}}$ phase of the sequential analysis, and the corresponding TS analysis: (a) and (b) show the ratio of maximum inter-storey drift versus $S_{\mathrm{a}}\left(T_{1}\right)$ and $F_{\mathrm{T}}$, respectively; (c) and (d) show the ratio of shear force in column 1011 versus $S_{\mathrm{a}}\left(T_{1}\right)$ and $F_{\mathrm{T}}$, respectively.

The ratios of the maximum values of the shear force in column 1011 occurring during the tsunami phase for the two sets of analyses, i.e., $V_{\mathrm{TS}, \mathrm{EQ}-\mathrm{TS}} / V_{\mathrm{TS}}$, are plotted against $S_{\mathrm{a}}\left(T_{1}\right)$ and $F_{\mathrm{T}}$ in Figures $4 \mathrm{c}$ and d, respectively. It can be seen that the larger the tsunami force, the smaller the impact of the preceding earthquake on the column shear force. The column shear during 
the tsunami phase is clearly correlated to the applied tsunami force. Thus it is expected that the $4 b)$.

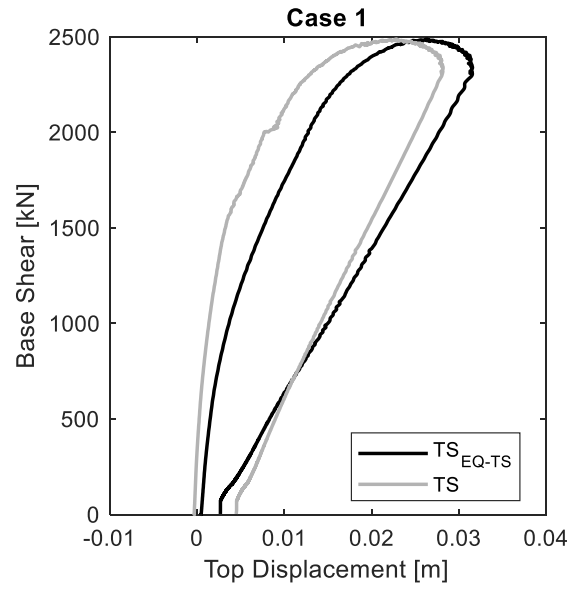

(a)

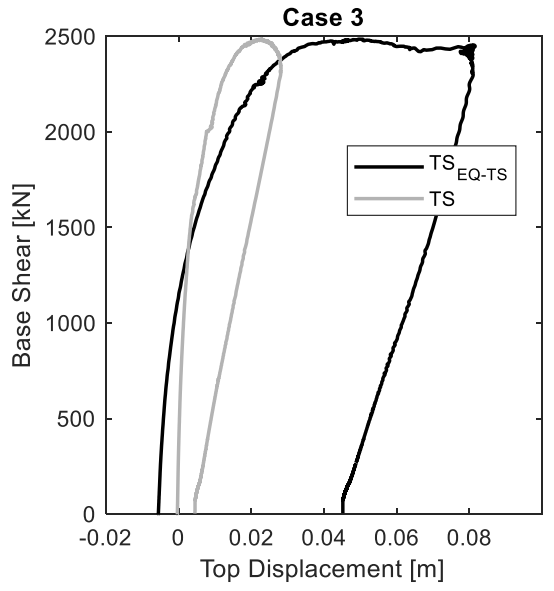

(c)

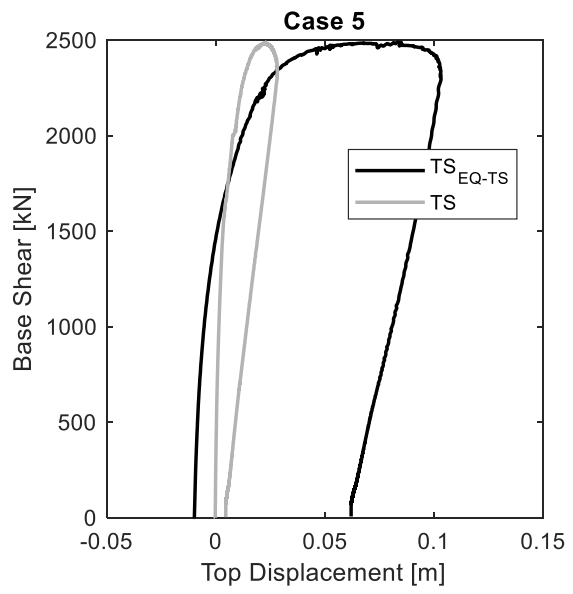

(e)

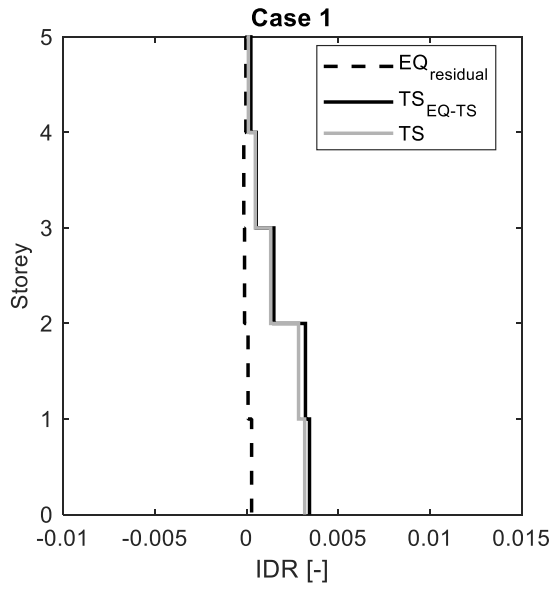

(b)

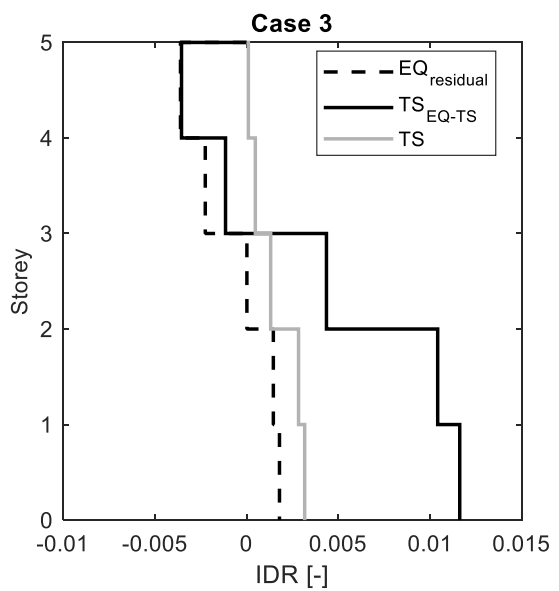

(d)

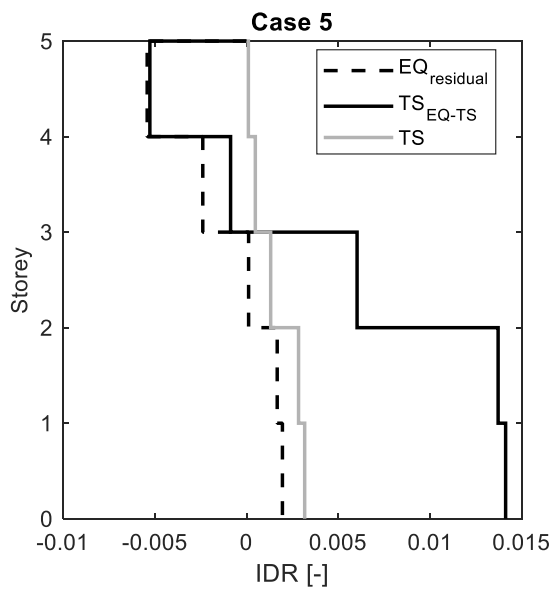

(f)

Figure 5. Comparison between the structure response under $\mathrm{TS}_{\mathrm{EQ}-\mathrm{TS}}$ phase of the sequential analysis, and the corresponding TS tsunami. In the sequential analysis, the building is subjected to the same tsunami wave trace, after having experienced increasingly-scaled ground motion records ('Case 1', 'Case 3' and 'Case 5'):

(a, c, e) show the base shear-roof drift response; and (b, d, f) show the maximum IDR profile along the height of the structure. 
Figure 5 compares the results from three representative analyses that are indicated as 'Case 1', 'Case 3' and 'Case 5' in Figure 4. These cases compare the response of the structure to the ground motion and tsunami pair recorded at one of the sites considered herein. While the tsunami force time-history is the same in all the analyses, the ground motion is unscaled in Case 1, amplified by a factor of 3 in Case 3 and scaled by a factor of 5 in Case 5. This comparison allows the assessment of the impact of the preceding ground motion on the following tsunami response, considering different levels of ground motion intensity. Figures $5 \mathrm{a}, \mathrm{c}, \mathrm{e}$ plot the force-top displacement response of the three considered cases, and compare these to the corresponding response for tsunami only actions. Following the earthquake, a noticeable difference in the global stiffness of the structure is observed. For instance, a decrease in initial stiffness of 39\%, 49\% and 55\% is seen for cases Cases 1, 3 and 5, respectively. Figures the earthquake cases, with the residual drift at the end of the earthquake phase also illustrated. These figures show that the structure sustains an increasing level of earthquake residual drift in the ground storey from Case 1 to Case 5. Moreover, as the ground motion intensity increases, the increased damage in the structure causes a higher degradation in the tsunami stiffness, i.e. the stiffness of the structure under the tsunami, and, thus, a noticeable difference in the resulting peak tsunami IDR. It is also interesting to note that the reduction in the tsunami stiffness results in a significant increase in the tsunami peak displacement response even in cases when the residual displacement following the ground motion phase is in the opposite direction to the applied tsunami load. This observation suggests that the stiffness reduction due to the earthquake loading has a greater influence on the tsunami displacement response than residual deformation or its direction. It is highlighted that if earthquake pushover were used instead of response history analyses, then residual drifts would be larger and it would be important to consider their direction [30].

\subsection{IMPACT OF EARTHQUAKE-TSUNAMI SEQUENCES ON STRUCTURAL}

315 DAMAGE STATE

Within this Section, the damage state definitions presented in Table 1 are used to attribute the structure response to a damage state. In the following, a distinction is made between cases where $d s 4$ is determined: (1) only from the global and storey-level damage criteria of Table 1, herein termed "global" performance, or (2) from the global, storey and member-level damage criteria of Table 1, herein termed "local". This distinction allows for an understanding of the effect of local shear failure on the overall structure performance. 


\subsubsection{Damage characterisation for tsunami time-history analysis}

Figures 6a and b show the distribution of damage states for the TS time-history analysis, adopting $d s 4$ definitions based on global and local performance, respectively. In both cases, there is a noticeable lack of intermediate damage states in the tsunami only analyses. Particularly, when the shear failure of column 1011 is accounted for (i.e. the local performance criterion for $d s$ ), damage states are either $d s 0$ or $d s 4$. Such a trend indicates that the tsunami induces a binary response, being either no damage or collapse, confirming the hypothesis of Rossetto et al. [30].

Figures $6 \mathrm{c}$ and $d$ show the distribution of IDR and SSF values plotted against $F_{\mathrm{T}}$ for the same set of time-history analysis. The results indicate that the magnitude of $F_{\mathrm{T}}$ describes well the damage of the structure. For instance, when $F_{\mathrm{T}}<2,000 \mathrm{kN}$, the induced IDR are below the slight damage $(d s 1)$ threshold in most of the analysis, and the column is not prone to shear failure. With increasing values of $F_{\mathrm{T}}$, the global response of the structure is characterised by larger IDR while, at member level, the column at the ground floor is highly likely to sustain shear failure, with SSF values being consistently less than 1.

\subsubsection{Damage characterisation for sequential earthquake and tsunami analysis}

The damage state histogram for the EQ-TS analysis is plotted in Figure 6a and b, adopting $d s 4$ definitions based on global and local performance, respectively. It is noted that the final damage state $\left(d s_{\mathrm{EQ}-\mathrm{TS}}\right)$ is defined as the maximum $d s$ achieved in any of the two analysis phases. Comparison with the TS results shows that in all EQ-TS analysis cases the RC frame experiences at least slight damage, with no $d s 0$ occurrences. Intermediate damage states $(d s 1$ to $d s 3$ ) are in fact mainly influenced by the earthquake ground shaking. This is apparent from the almost total absence of intermediate damage states in the TS case, and larger number of such damage state cases for EQ-TS.

The collapse performance of the RC frame is instead dominated by the tsunami, with the preceding earthquake only slightly increasing the number of $d s 4$ cases when compared to the tsunami only analyses (less than 1\%). This is particularly true when the local performance is considered, with shear failure of local elements precipitating structural failure under the tsunami (i.e., $d s 4$ cases increase from around $20 \%$ to $40 \%$ when local performance is considered). This finding also indicates that the collapse likelihood of the considered RC frame would be substantially reduced by increasing the shear resistance of the ground floor columns. 


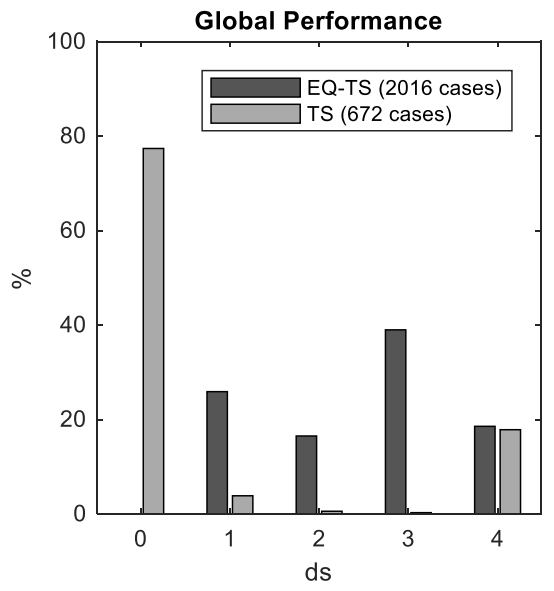

(a)

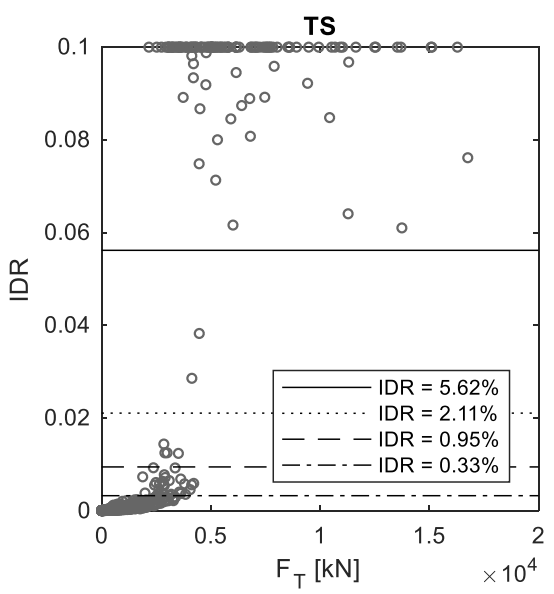

(c)

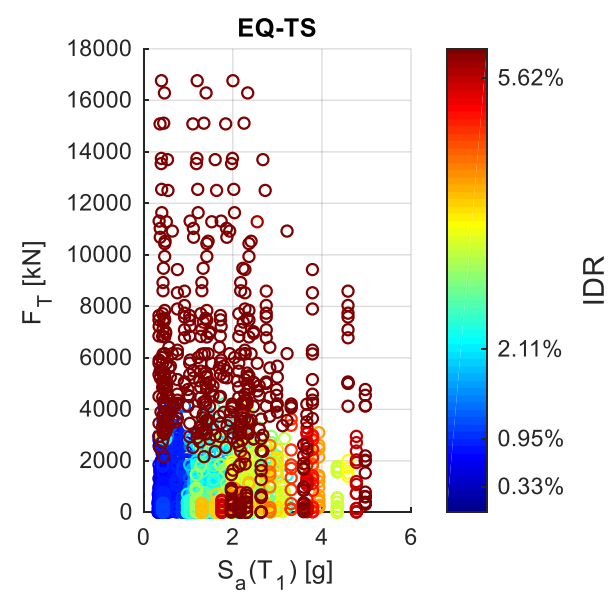

(e)

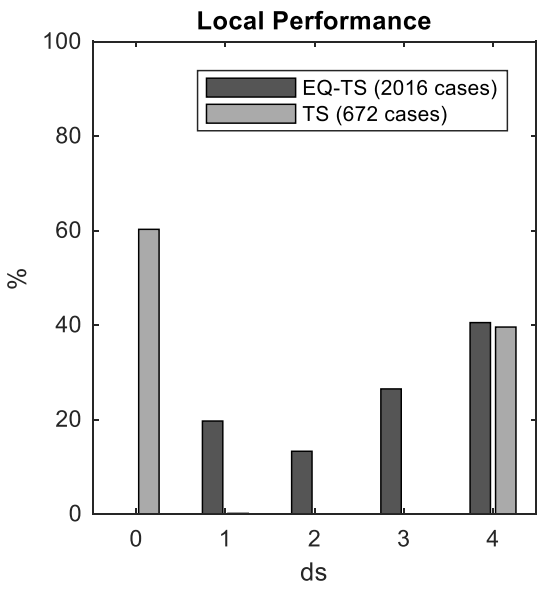

(b)

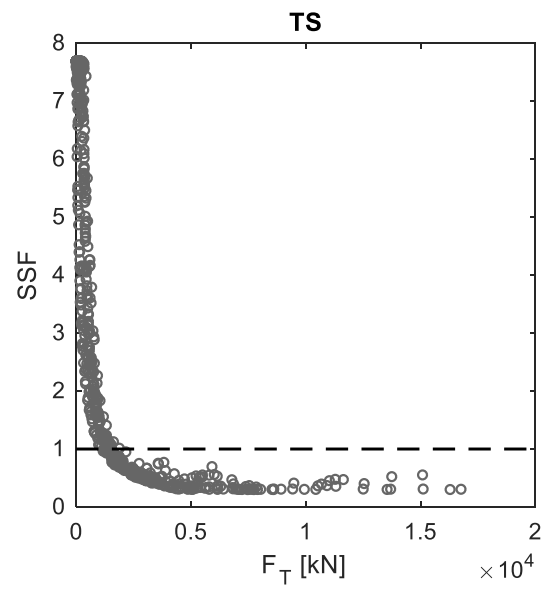

(d)

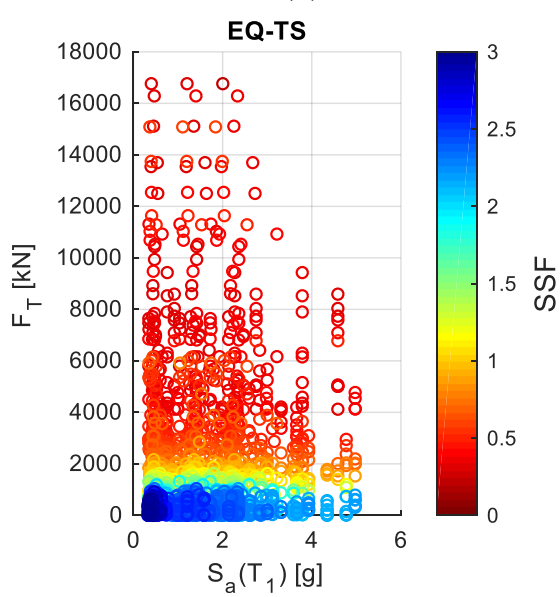

(f)

Figure 6. (a) and (b) the distribution of damage states for earthquake-tsunami (EQ-TS) analysis and tsunami with no earthquake analysis (TS), in terms of global and local performance, respectively; (c) and (d) IDR and

SSF from TS analysis, respectively, plotted against $F_{\mathrm{T}}$; (e) and (f) IDR and SSF from EQ-TS analysis, respectively, plotted against $S_{\mathrm{a}}\left(T_{1}\right)$ and $F_{\mathrm{T}}$.

The distribution of IDR values plotted against $S_{\mathrm{a}}\left(T_{1}\right)$ and $F_{\mathrm{T}}$ in Figure 6e confirms that for $F_{\mathrm{T}}<2,000 \mathrm{kN}$ the structural response in terms of inter-storey drift ratio mainly depends on the earthquake intensity. However, the ground motion influence on the IDR response becomes 
negligible for $F_{\mathrm{T}}$ values larger than this. Figure $6 f$ plots the SSF values against $S_{\mathrm{a}}\left(T_{1}\right)$ and $F_{\mathrm{T}}$ and proves that tsunami-induced shear forces control the local performance of the RC frame, since SSF $<1$ when $F_{\mathrm{T}}$ exceeds 1,500-2000 kN, irrespectively of the ground motion intensity.

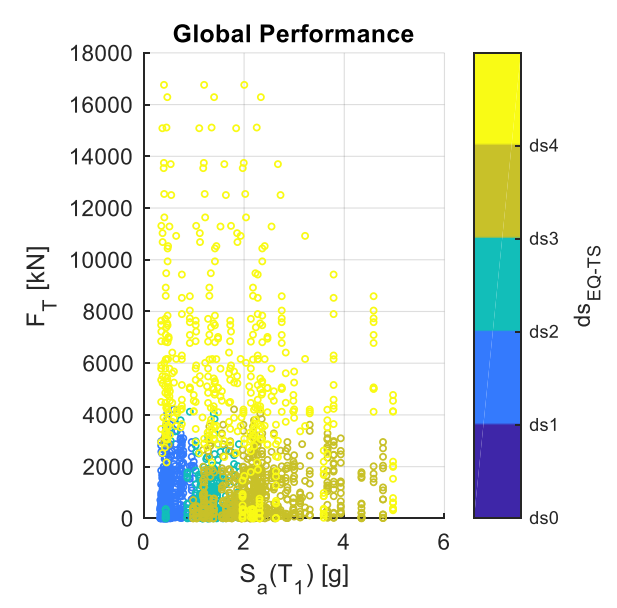

(a)

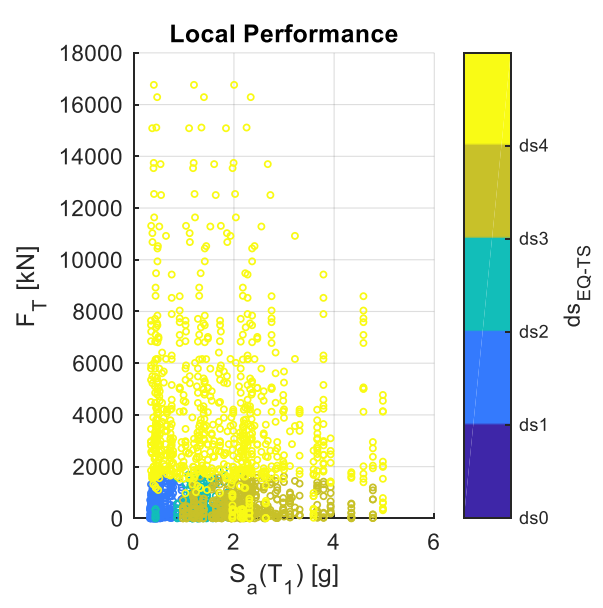

(b)

Figure 7. Damage state distribution under sequential earthquake and tsunami (EQ-TS) in terms of earthquake and tsunami IMs: (a) global performance; and (b) local performance.

Figure 7 presents the distribution of $d s_{\mathrm{EQ}-\mathrm{TS}}$ versus the earthquake and tsunami IMs for both global and local performance. When local performance is considered (Figure $7 \mathrm{~b}$ ), $F_{\mathrm{T}}=1,500$ $\mathrm{kN}$ clearly appears to be the threshold of structural collapse $(d s 4)$. When the shear failure of column 1011 is not accounted for, (Figure 7a), collapse is typically attained at larger tsunami peak forces, i.e., about 3,000 kN. For tsunami force values below this threshold, the damage progression is primarily defined by the structure response to the earthquake loading. It is interesting to note that $S_{\mathrm{a}}\left(T_{1}\right)=2 \mathrm{~g}$ represents the threshold of $d s 4$ for both global and local performance.

\subsection{FRAGILITY ASSESSMENT}

The fragility assessment of the $\mathrm{RC}$ frame under sequential earthquake and tsunami aims to quantify: (a) the influence of prior seismic damage on tsunami fragility; and (b) the likelihood of collapse when the building is subjected to earthquake and tsunami in sequence.

\subsubsection{Do tsunami fragility curves depend on the prior seismic damage?}

To answer this question, the EQ-TS analysis results are considered in three groups, with each group defined by the damage sustained at the end of the tsunami leading phase, i.e. for (a) tsunami damage greater or equal to moderate damage, $D S_{\mathrm{TS}} \geq d s 2_{\mathrm{TS}}$; (b) tsunami damage greater or equal to extensive damage, $D S_{\mathrm{TS}} \geq d s 3_{\mathrm{TS}}$; and (c) tsunami collapse, $D S_{\mathrm{TS}} \geq d s 4_{\mathrm{TS}}$. For each group (a), (b) and (c), the analysis data is further sub-divided by the damage level 
sustained following the earthquake loading phase, i.e. $d s 1_{\mathrm{EQ}}, d s 2_{\mathrm{EQ}}, d s 3_{\mathrm{EQ}}$. In this study, no cases with $d s 0_{\mathrm{EQ}}$ were observed due to the low IDR threshold used for $d s 1$. All data regarding the tsunami only analyses (TS) are also included, with $N o E Q$. A probit model is fitted to these subsets as:

$$
I=\left\{\begin{array}{l}
1 \text { if } D S_{\mathrm{TS}} \geq d s \mathrm{i}_{\mathrm{TS}} \\
0 \text { if } D S_{\mathrm{TS}}<d s \mathrm{i}_{\mathrm{TS}}
\end{array}, \quad \quad \operatorname{binomial}\left(P\left(D S_{\mathrm{TS}} \geq d s \mathrm{i}_{\mathrm{TS}} \mid F_{\mathrm{T}}, D S_{\mathrm{EQ}}\right)\right)\right.
$$

where the mean fragility curve is obtained as:

$$
\Phi^{-1}\left[P\left(D S_{\mathrm{TS}} \geq d s i_{\mathrm{TS}} \mid F_{\mathrm{T}}, D S_{\mathrm{EQ}}\right]=\theta_{0}+\theta_{1} \ln \left(F_{\mathrm{T}}\right)\right.
$$

and where $\theta_{0}$ and $\theta_{1}$ are the regression coefficients (the intercept and the slope, respectively). $F_{T}$ corresponds to the peak value of the associated tsunami time-series. In order for the results to be easily compared with existing studies, the parameters of the best-estimate fragility curves are presented in terms of their median, $F_{T, m}$, and lognormal standard deviation, $\beta$, are derived as:

$$
\begin{gathered}
F_{T, m}=\exp \left(-\frac{\theta_{0}}{\theta_{1}}\right) \\
\beta=\frac{1}{\theta_{1}}
\end{gathered}
$$

Figure 8 shows the tsunami fragility curves and their $90 \%$ confidence intervals conditioned to prior seismic damage for both performance levels, i.e., global and local. The confidence intervals appear to be close to the best-estimate fragility curves, which is expected given the relatively large damage data used in the fragility assessment. As illustrated in Figure 8a, the likelihood of building collapse under tsunami increases slightly when it experiences either a moderate or a major level of damage during the preceding ground shaking. For example, the fragility curves of the structures with at least an initial moderate damage ( $d s 2$ ) show a $10 \%$ drop in the median collapse tsunami force when compared to the structures subjected to tsunami only (Table 2). On the contrary, a negligible impact on the tsunami fragility curve is observed for cases when the earthquake results in slight damage $\left(d s 1_{\mathrm{EQ}}\right)$.

It can be concluded that there is a step-wise correlation between tsunami collapse and the severity of prior seismic damage. The level of the preceding earthquake damage does not significantly influence the tsunami fragility unless it induces yield in the first-storey columns, i.e. the initial damage state is $\geq d s 2$. If the earthquake induces yielding in the ground floor columns of the structure, the stiffness of the structure under the subsequent tsunami is 
402

403

404

405

406

significantly reduced, resulting in larger structural deformation. This increased structural deformation, in turn, causes an increase in P-delta effects under the tsunami actions with consequent reduction in the structure base shear capacity. However, it is noted that the impact of the preceding ground motion on the tsunami performance of the investigated structure is quite limited, with the peak tsunami strength reduction never exceeding $15 \%$.

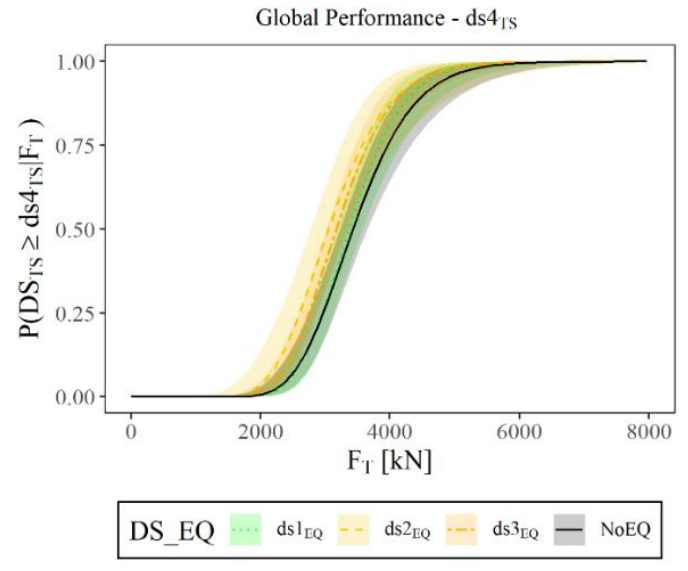

(a)

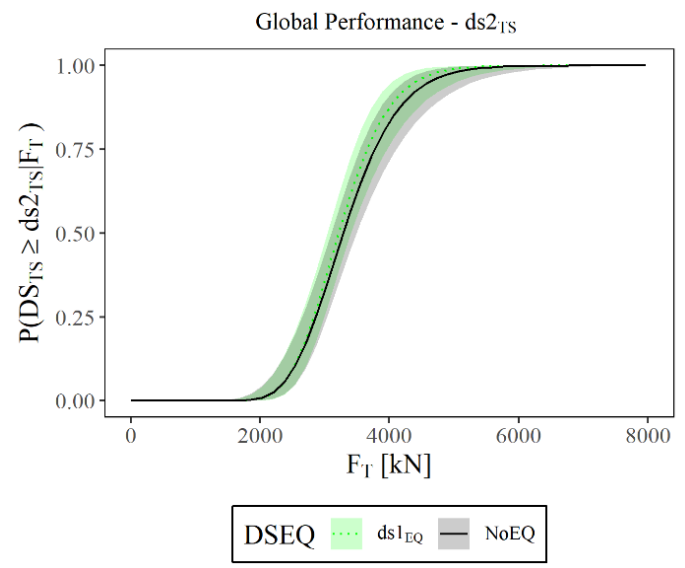

(c)

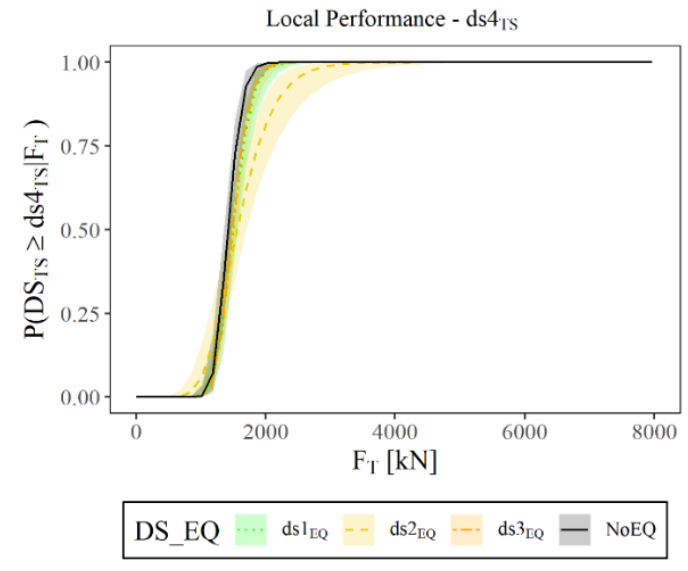

(b)

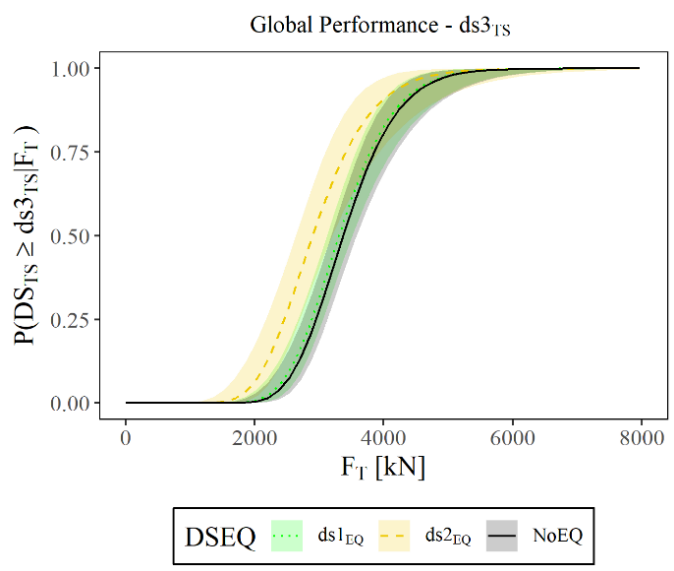

(d)

Figure 8. Fragility functions and their $90 \%$ confidence intervals conditioned to prior seismic damage and exposed only to tsunami: (a,c,d) global performance; and (b) local performance.

407

408

409

410

411

412

413

414

If the shear failure of columns is accounted for (Figure 8b), the results confirm that the preceding earthquake does not influence the fragility of the $\mathrm{RC}$ frame under tsunami. It is observed that the tsunami force that causes the shear failure in a column can even slightly increase as a result of the preceding ground motion. Such an increase can be justified by the residual earthquake deformation in the opposite direction that induces P-delta effects in the structure and reduces the force in the column at the ground floor, hence requiring a slightly larger tsunami force to reach the shear capacity in the column. It is noted here that due to the small sample size, the fragility function derived for $\mathrm{DS}_{\mathrm{Ts}} \geq \mathrm{ds}_{\mathrm{TS}} \mid \mathrm{ds} 2_{\mathrm{EQ}}$ is not deemed reliable. 
The results indicate that the fragility of seismically designed structures can be approximated by assessing the earthquake and tsunami response separately, confirming the hypothesis proposed in Rossetto et al. [30]. This reflects the fundamentally different response of the structure to both perils: while the ground motion response of the structure is governed by its strength, ductility and stiffness, the tsunami performance of the structure is dominated by its strength.

It can be noted that the slope of the tsunami fragility curve, determined here in terms of $\beta$ (see Table 2), is steep and not influenced by the preceding ground motion. It is noted that the slightly higher beta values presented here with respect to Petrone et al. [9] are deemed consistent with the fact that a different structure is analysed and that a smaller number of analyses is used for the fragility function derivation. Furthermore, as each earthquake damage state covers a range of EDPs, there is a variation in the structural properties associated with any damage state at the end of the earthquake loading phase. This results in an additional source of variation in the tsunami response of the structure. It can therefore be concluded that the fragility curves presented here confirm the findings of Petrone et al. [9] that $F_{\mathrm{T}}$ is a highly efficient intensity measure for tsunami fragility function development.

Table 2. Median tsunami force and lognormal standard deviation considering either global or local performance damage states

\begin{tabular}{lcccccc}
\hline & \multicolumn{3}{c}{ Global Performance } & \multicolumn{3}{c}{ Local Performance } \\
\cline { 2 - 7 } & $\boldsymbol{F}_{\boldsymbol{T}, \boldsymbol{m}}$ & $\boldsymbol{\beta}$ & Sample & $\boldsymbol{F}_{\boldsymbol{T}, \boldsymbol{m}}$ & $\boldsymbol{\beta}$ & Sample \\
\hline $\mathrm{DS}_{\mathrm{TS}} \geq \mathrm{ds} 2_{\mathrm{TS}} \mid \mathrm{NoEQ}$ & 3262 & 0.20 & $126 / 2688$ & & & \\
$\mathrm{DS}_{\mathrm{TS}} \geq \mathrm{ds} 2_{\mathrm{TS}} \mid \mathrm{ds} 1_{\mathrm{EQ}}$ & 3229 & 0.19 & $129 / 2688$ & & & \\
\hline $\mathrm{DS}_{\mathrm{TS}} \geq \mathrm{ds} 3_{\mathrm{TS}} \mid \mathrm{NoEQ}$ & 3395 & 0.20 & $122 / 2688$ & & & \\
$\mathrm{DS}_{\mathrm{TS}} \geq \mathrm{ds} 3_{\mathrm{TS}} \mid \mathrm{ds} 1_{\mathrm{EQ}}$ & 3328 & 0.20 & $125 / 2688$ & & & \\
$\mathrm{DS}_{\mathrm{TS}} \geq \mathrm{ds} 3_{\mathrm{TS}} \mid \mathrm{ds} 2_{\mathrm{EQ}}$ & 2922 & 0.24 & $77 / 2688$ & & & \\
\hline $\mathrm{DS}_{\mathrm{TS}} \geq \mathrm{ds} 4_{\mathrm{TS}} \mid \mathrm{NoEQ}$ & 3429 & 0.21 & $120 / 2688$ & 1408 & 0.12 & $266 / 2688$ \\
$\mathrm{DS}_{\mathrm{TS}} \geq \mathrm{ds} 4_{\mathrm{TS}} \mid \mathrm{ds} 1_{\mathrm{EQ}}$ & 3361 & 0.19 & $122 / 2688$ & 1495 & 0.15 & $251 / 2688$ \\
$\mathrm{DS}_{\mathrm{TS}} \geq \mathrm{ds} 4_{\mathrm{TS}} \mid \mathrm{ds} 2_{\mathrm{EQ}}$ & 3041 & 0.23 & $74 / 2688$ & 1556 & 0.28 & $126 / 2688$ \\
$\mathrm{DS}_{\mathrm{TS}} \geq \mathrm{ds} 4_{\mathrm{TS}} \mid \mathrm{ds} 3_{\mathrm{EQ}}$ & 3165 & 0.21 & $177 / 2688$ & 1480 & 0.14 & $352 / 2688$ \\
\hline
\end{tabular}




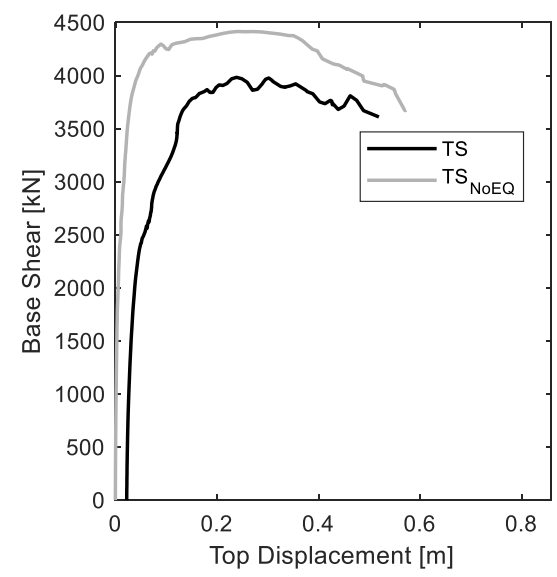

(a)

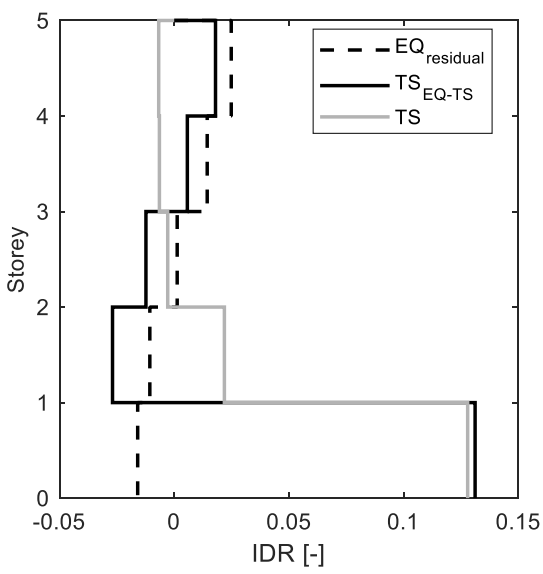

(b)

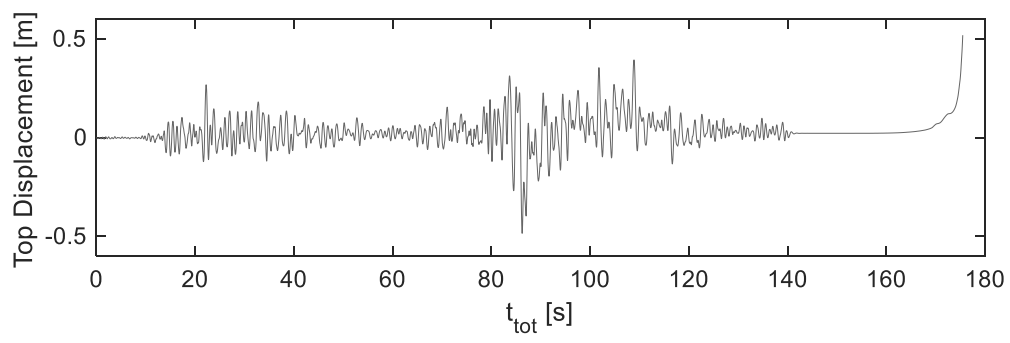

(c)

Figure 9. Comparison between the structure response under one of $\mathrm{TS}_{\mathrm{EQ}} \mathrm{TS}$ phase of the sequential analysis, and the corresponding tsunami considered in this study: (a) base shear-roof drift response; and (b) maximum IDR profile along the height of the structure; and (c) top displacement time-history for the sequential EQ-TS analysis.

433 In Figure 9, the structural response recorded for a ground motion-tsunami pair that induces $d s 4$ 434 at the end of the analysis, is compared to the corresponding tsunami-only analysis to further 435 highlight how earthquake damage influences tsunami performance. In this specific case, the 436 sustained earthquake damage reduces the structural stiffness under the tsunami, and the resulting increase in P-delta effects cause a $\sim 10 \%$ reduction in tsunami strength. Once the 438 tsunami strength is saturated, the structure exhibits a sudden increase in lateral displacement 439 up to failure, as shown in the time history plot (Figure 9c). Figure 9b shows a plot of maximum 440 inter-storey drift for the tsunami only and tsunami preceded by the earthquake cases, with the 441 residual drift at the end of the earthquake phase also illustrated. This plot confirms that the 442 structure forms a soft-storey mechanism after its peak tsunami strength is achieved. The same 443 failure mechanism is observed for both cases where the tsunami is preceded or not by the earthquake. 


\subsubsection{What is the collapse likelihood of the building under sequential earthquake and} tsunami?

The total probability theorem is used to determine the probability of collapse of buildings affected by the earthquake and subsequent tsunami:

$$
\begin{aligned}
& P\left(D S_{\mathrm{EQ}-\mathrm{TS}} \geq d s 4_{\mathrm{EQ}-\mathrm{TS}} \mid S_{\mathrm{a}}\left(T_{1}\right), F_{\mathrm{T}}\right)= \\
& =\sum_{i=0}^{4} P\left(D S_{\mathrm{EQ}-\mathrm{TS}} \geq d s 4_{\mathrm{EQ}-\mathrm{TS}} \mid S_{\mathrm{a}}\left(T_{1}\right), F_{\mathrm{T}}, d s \mathrm{i}_{\mathrm{EQ}}\right) P\left(D S_{\mathrm{EQ}}=d s \mathrm{i}_{\mathrm{EQ}} \mid S_{\mathrm{a}}\left(T_{1}\right), F_{\mathrm{T}}\right) \\
& =\sum_{i=0}^{4} P\left(D S_{\mathrm{EQ}-\mathrm{TS}} \geq d s 4_{\mathrm{EQ}-\mathrm{TS}} \mid F_{\mathrm{T}}, d s \mathrm{i}_{\mathrm{EQ}}\right) P\left(D S_{\mathrm{EQ}}=d s \mathrm{i}_{\mathrm{EQ}} \mid S_{\mathrm{a}}\left(T_{1}\right)\right) \\
& =P\left(D S_{\mathrm{TS}} \geq d s 4_{\mathrm{TS}} \mid F_{\mathrm{T}}, d s 0_{\mathrm{EQ}}\right) P\left(D S_{\mathrm{EQ}}=d s 0_{\mathrm{EQ}} \mid S_{\mathrm{a}}\left(T_{1}\right)\right) \\
& +P\left(D S_{\mathrm{TS}} \geq d s 4_{\mathrm{TS}} \mid F_{\mathrm{T}}, d s 1_{\mathrm{EQ}}\right) P\left(D S_{\mathrm{EQ}}=d s 1_{\mathrm{EQ}} \mid S_{\mathrm{a}}\left(T_{1}\right)\right) \\
& +P\left(D S_{\mathrm{TS}} \geq d s 4_{\mathrm{TS}} \mid F_{\mathrm{T}}, d s 2_{\mathrm{EQ}}\right) P\left(D S_{\mathrm{EQ}}=d s 2_{\mathrm{EQ}} \mid S_{\mathrm{a}}\left(T_{1}\right)\right) \\
& +P\left(D S_{\mathrm{TS}} \geq d s 4_{\mathrm{TS}} \mid F_{\mathrm{T}}, d s 3_{\mathrm{EQ}}\right) P\left(D S_{\mathrm{EQ}}=d s 3_{\mathrm{EQ}} \mid S_{\mathrm{a}}\left(T_{1}\right)\right) \\
& +P\left(D S_{\mathrm{EQ}}=d s 4_{\mathrm{EQ}} \mid S_{\mathrm{a}}\left(T_{1}\right)\right)
\end{aligned}
$$

Essentially, the overall probability of collapse is determined by the probability of collapse during the earthquake and the probability of collapse during the tsunami, given the seismic damage state weighted by the probability of sustaining this seismic damage state. The probability that the building will sustain a certain seismic damage state $\left(d s \mathrm{i}_{\mathrm{EQ}}\right)$ is estimated as:

$$
P\left(D S_{\mathrm{EQ}}=d s i_{\mathrm{EQ}} \mid S_{\mathrm{a}}\left(T_{1}\right)\right)=\left\{\begin{array}{c}
1-P\left(D S_{\mathrm{EQ}} \geq d s(\mathrm{i}+1)_{\mathrm{EQ}} \mid S_{\mathrm{a}}\left(T_{1}\right)\right) \text { if } \mathrm{i}=0 \\
P\left(D S_{\mathrm{EQ}} \geq d s \mathrm{i}_{\mathrm{EQ}} \mid S_{\mathrm{S}}\left(T_{1}\right)\right)-P\left(D S_{\mathrm{EQ}} \geq d s(\mathrm{i}+1)_{\mathrm{EQ}} \mid S_{\mathrm{a}}\left(T_{1}\right)\right) \text { if } 1 \leq \mathrm{i}<4 \\
P\left(D S_{\mathrm{EQ}} \geq d s \mathrm{i}_{\mathrm{EQ}} \mid S_{\mathrm{a}}\left(T_{1}\right)\right) \text { if } \mathrm{i}=4
\end{array}\right.
$$

The probability that the building will reach or exceed a given damage state conditional on the spectral acceleration can be obtained by the seismic fragility curves, i.e., $P\left(D S_{\mathrm{EQ}} \geq\right.$ $\left.d s \mathrm{i}_{\mathrm{EQ}} \mid S_{\mathrm{a}}\left(T_{1}\right)\right)$, corresponding to seismic damage states $d s 2_{\mathrm{EQ}}$ to $d s 4_{\mathrm{EQ}}$. These are constructed by fitting a probit model to the data:

$$
\mathrm{I}=\left\{\begin{array}{l}
1 \text { if } D S_{\mathrm{EQ}} \geq d s \mathrm{i}_{\mathrm{EQ}} \\
0 \text { if } D S_{\mathrm{EQ}}<d s \mathrm{i}_{\mathrm{EQ}}
\end{array}, \quad \operatorname{binomial}\left(P\left(D S_{\mathrm{EQ}} \geq d s \mathrm{i}_{\mathrm{EQ}} \mid S_{\mathrm{a}}\left(T_{1}\right)\right)\right)\right.
$$

where the mean fragility curve is obtained as:

$$
\Phi^{-1}\left[P\left(D S_{\mathrm{EQ}} \geq d s \mathrm{i}_{\mathrm{EQ}} \mid S_{\mathrm{a}}\left(T_{1}\right)\right]=\theta_{0}+\theta_{1} \ln \left(S_{\mathrm{a}}\left(T_{1}\right)\right)\right.
$$

Figure 10 shows the collapse fragility surface for the building exposed to both earthquake and tsunami. The collapse fragility surface is almost constant across different ground motion 
460

461

462

463

464

465

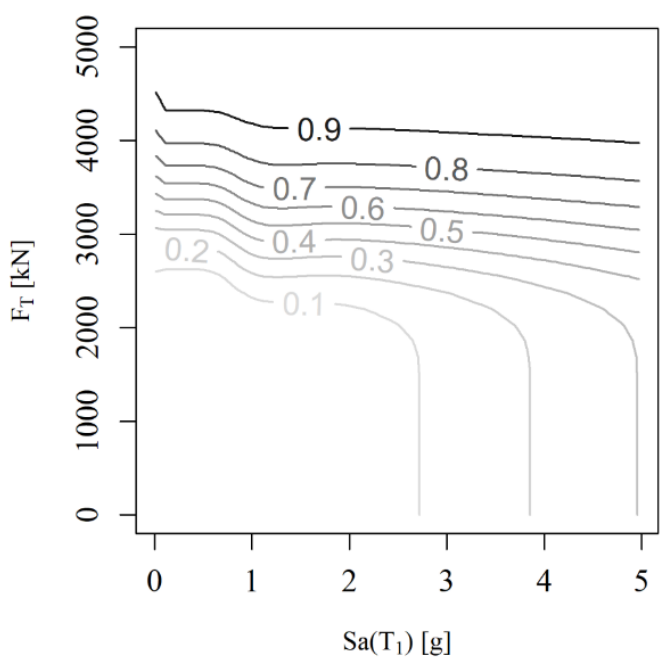

(a)

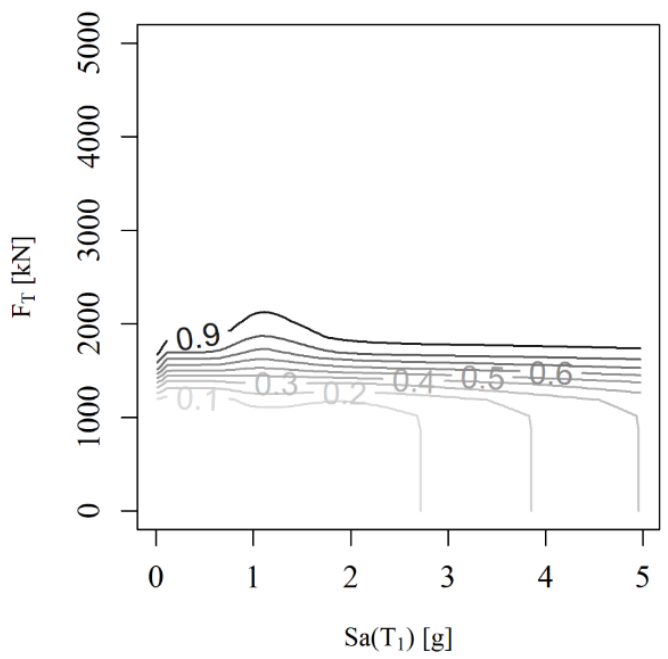

(b)

Figure 10. Collapse fragility surface for the building under sequential earthquake and tsunami: (a) global

466

467

468

469

470

471

472

473

474

475

476

477

478

479

intensity levels, and is only influenced by the ground motion intensity once this exceeds very large spectral acceleration values, e.g. $S_{\mathrm{a}}\left(T_{1}\right) \sim 2.7 \mathrm{~g}$ for $10 \%$ probability of failure. This confirms the previous observation that the intensity of the ground motion does not play a significant role on the tsunami response of the structure unless it induces structural yield. This observation, coupled with the shape of the joint fragility curve suggesting that the two perils can be treated independently in terms of structural analysis.

\footnotetext{
performance; and (b) local performance.
}

When shear failure of the columns is considered, the contours of the collapse fragility surface appear to be very close to each other and characterised by a much smaller value of the median collapse tsunami force. In this case, the ground motion intensity shows a negligible impact on the median collapse tsunami force, further suggesting that the structure can be assessed separately for the earthquake and tsunami loads. It is noted that the kink in the fragility surface contours is likely caused by the adopted dataset, which shows fewer data points around $S_{\mathrm{a}}\left(T_{1}\right)=1.0 \mathrm{~g}$. However, the 0.5 contour line does not show a kink and only the very high and very low probability of exceedance contour lines are affected.

\section{CONCLUSIONS}

This study investigates the response of a seismically designed reinforced concrete frame structure to tsunami inundation only, and to earthquake ground motion and tsunami inundation in sequence. Comparison of these analyses allows for an assessment to be made of the impact of the preceding ground motion on the subsequent tsunami response of the structure. Realistic ground motion and tsunami inundation time histories have been simulated considering a 
seismic source representative of the M9 2011 Tohoku earthquake event. The key findings of the study are summarised as follows:

- The preceding ground motion only slightly influences the final earthquake and tsunami fragility functions. Such influence is negligible if the damage sustained during the ground shaking phase is less than moderate (i.e. unless the structure yields under the tsunami). Structural yield under the earthquake excitation, leads to a reduced structure stiffness when the tsunami inundation hits. This in turn causes greater P-delta effects under tsunami actions, resulting in significantly larger induced permanent displacement of the structure. However, only a small reduction in the structure's tsunami strength is observed.

- The fragility curves constructed for the cascading hazards show $<15 \%$ reduction in the median tsunami force as compared to the fragility functions for tsunami only. Moreover, the initial damage state induced by the ground shaking does not influence the uncertainty of the tsunami fragility curves. There is therefore only a small influence of the preceding earthquake ground shaking on the tsunami fragility.

- The small impact of the ground motion on tsunami fragility is caused by the fundamentally different response of the structure to the two perils. The structural strength under tsunami is different from the strength under earthquake loading, due to the different nature of the two perils. Furthermore, while the ground motion response of the structure is governed by its strength, ductility and stiffness, the tsunami performance of the structure is dominated by its strength. The results of the current study therefore seem to confirm the hypothesis of Rossetto et al. [30], that the fragility of seismically designed structures can be approximated by assessing the earthquake and tsunami response separately.

- Tsunami analyses show a clear lack of intermediate (structural) damage states with the structure moving from the initial earthquake-induced damage state to collapse as soon as the structural strength under tsunami loading is exceeded. Under the cascading hazard analysis, it is also observed that the analyses resulting in damage states between none and collapse are those where the ground-shaking determines the damage state, with the structure not suffering a larger damage under the tsunami.

- Despite the structure being seismically designed, column shear failure is found to govern the attainment of the collapse damage state in the considered structure under the tsunami actions. This suggests that the lower storey columns need to be designed 
specifically for the shear actions induced by the tsunami. Shear failure under tsunami loading is found to be only slightly influenced by the preceding ground motion.

It is worth noting that the tsunami response of the case-study structure is evaluated considering only the effects of the tsunami-induced hydrodynamic force. Other possible effects caused by tsunami, e.g. buoyancy, debris impact, scour, as defined in ASCE 7-16 Standard [32], were not considered in this study. Moreover, the earthquake-tsunami pairs used in this study were estimated at the same locations from numerical simulations. A separate study will assess the efficiency and sufficiency of alternative intensity measures for earthquake and tsunami in sequence. Future work will also evaluate the impact of earthquake damage on the tsunami response of non-seismically designed reinforced concrete structures, where columns typically show shear degradation during the earthquake, thus increasing the potential impact of the ground motion damage on the tsunami fragility of structures.

\section{ACKNOWLEDGEMENTS}

This work was supported by the European Research Council URBANWAVES grant [ERC Starting Grant 336084], awarded to Professor Tiziana Rossetto. The authors also acknowledge Willis Towers Watson for supporting the time of Dr Crescenzo Petrone.

\section{REFERENCES}

[1] CRED (2015). The human cost of natural disasters - A global perspective. Centre for Research on the Epidemiology of Disasters. UNISDR.

[2] Kajitani Y., Chang S.E., and Tatano H. (2013). Economic Impacts of the 2011 Tohoku-Oki Earthquake and Tsunami. Earthquake Spectra, 29(S1), pp. S457-S478.

[3] Sundermann L., Schelske O., and Hausmann P. (2014). Mind the risk - A global ranking of cities under threat from natural disaster. Swiss Re, Report No. 1505715_13_en12/14.

[4] Goda K., Rossetto T., Mori N., Tesfamariam S. (2018). Editorial: Quakes: Cascading Earthquake Hazards and Compounding Risks. Frontiers in Built Environment, 4, pp. 1-3.

[5] Suppasri A., Koshimura S., and Imamura F. (2011). Developing tsunami fragility curves based on the satellite remote sensing and the numerical modeling of the 2004 Indian Ocean tsunami in Thailand. Natural Hazards and Earth System Sciences, 11, 173-89.

[6] Macabuag J., Lloyd T., and Rossetto T. (2014). Towards the Development of a Method for Generating Analytical Tsunami Fragility Functions. In Second European Conference on Earthquake Engineering and Seismology, Istanbul, August 25-29 2014. 
545 [7] Nanayakkara K.I.U. and Dias W.P.S. (2016). Fragility curves for structures under tsunami loading. Natural Hazards, 80(1), pp. 471-486.

[8] Attary N., Unnikrishnan V.U., van de Lindt J.W., Cox D.T., and Barbosa A.R. (2017). Performance-Based Tsunami Engineering Methodology for Risk Assessment of Structures. Engineering Structures, 141, 676-686.

[9] Petrone C., Rossetto T., and Goda K. (2017). Fragility assessment of a RC structure under tsunami actions via nonlinear static and dynamic analyses. Engineering Structures, 136, pp. 36-53.

[10] Alam M.S., Barbosa A.R., Scott M.H., Cox D.T., and van de Lindt J.W (2018).

Development of Physics-Based Tsunami Fragility Functions Considering Structural Member Failures. Journal of Structural Engineering, 144(3), 04017221.

[11] Park S., van de Lindt J.W., Cox D., Gupta R., and Aguiniga F. (2012). Successive earthquake tsunami analysis to develop collapse fragilities. Journal of Earthquake Engineering, 16, 851-63.

[12] Rossetto T., De la Barra C., Petrone C., De la Llera J. C., Vazquez J., and Baiguera M. (2019). Comparison of Nonlinear Static and Dynamic Analysis Methods for Assessing Structural Response Under Earthquake and Tsunami in Sequence. Earthquake Engineering and Structural Dynamics 48, 867-887.

[13] Attary N., Van De Lindt J.W., Barbosa A.R., Cox D.T., and Unnikrishnan V.P. (2019).

Performance-Based Tsunami Engineering for Risk Assessment of Structures Subjected to Multi-Hazards: Tsunami following Earthquake. Journal of Earthquake Engineering, 1-20.

[14] Carey T.J., Mason H.B., Barbosa A.R., and Scott M.H. (2019). Multihazard earthquake and tsunami effects on soil-foundation-bridge systems. ASCE Journal of Bridge Engineering, 24(4), 04019004.

[15] Goda K., Petrone C., de Risi R., and Rossetto T. (2017). Stochastic coupled simulation of strong motion and tsunami for the 2011 Tohoku, Japan earthquake. Stochastic Environmental Research and Risk Assessment, 31(9), pp. 2337-2355.

[16] Japan Building Disaster Prevention Association (2007). Structural design-member cross-section case studies. Minister of Land, Infrastructure and Transport. Japan Building Disaster Prevention Association (in Japanese).

[17] Architectural Institute of Japan (1999). Standard for Structural Calculation of Reinforced Concrete Structures.

[18] Ministry of Land Infrastructure Transport and Tourism (2001). Commentary to Building Standard Law. The Building Center of Japan. 
[19] McKenna F. and Fenves G. (2013). OpenSees Manual. Berkeley, California. Available at: http://opensees.berkeley.edu.

[20] Architectural Institute of Japan (1988). Design guideline for earthquake resistant buildings based on ultimate strength concepts (in Japanese).

[21] Popovics S. (1973). A numerical approach to the complete stress strain curve for concrete. Cement and concrete research, 3(5), 583-599.

[22] Karsan I.D. and Jirsa J.O. (1969). Behavior of concrete under compressive loading. Journal of Structural Division ASCE, 95(ST12).

[23] Macabuag J. (2017). Tsunami Damage Prediction for Buildings: Development of Methods for Empirical and Analytical Fragility Function Derivation. Engineering Doctorate Thesis, University College London, London.

[24] Goda K., Yasuda T., Mori N., and Mai P.M. (2015). Variability of tsunami inundation footprints considering stochastic scenarios based on a single rupture model: Application to the 2011 Tohoku earthquake. Journal of Geophysics Research: Oceans, 120, pp. 4552-75.

[25] Goto C., Ogawa Y., Shuto N., and Imamura F. (1997). Numerical method of tsunami simulation with the leap-frog scheme (IUGG/IOC Time Project). UNESCO, Paris, France.

[26] Dao M.H. and Tkalich P. (2007). Tsunami propagation modelling ? A sensitivity study. Natural Hazards and Earth System Science, Copernicus Publications on behalf of the European Geosciences Union, 7 (6), pp.741-754.

[27] Qi Z.X., Eames I., and Johnson E.R. (2014). Force acting on a square cylinder fixed in a free-surface channel flow. Journal of Fluid Mechanics, 756, pp. 716-727.

[28] Rossetto T., Gehl P., Minas S., Galasso C., Duffour P., Douglas J., and Cook O. (2016). FRACAS: A capacity spectrum approach for seismic fragility assessment including recordto-record variability. Engineering Structures, 125, pp. 337-348.

[29] Federal Emergency Management Agency (2015). Hazus-MH 2.1: Technical Manual, National Institute of Building Sciences and Federal Emergency Management Agency (NIBS and FEMA). Available at: www.fema.gov/plan/prevent/hazus.

[30] Rossetto T., Petrone C., Eames I., De La Barra C., Foster A., and Macabuag J. (2018). Advances in the Assessment of Buildings Subjected to Earthquakes and Tsunami. In: Pitilakis K. (eds) Recent Advances in Earthquake Engineering in Europe. ECEE 2018. Geotechnical, Geological and Earthquake Engineering, vol 46. Springer, Cham

[31] Biskinis D.E., Roupakias G.K., and Fardis M.N. (2004). Degradation of shear strength of reinforced concrete members with inelastic cyclic displacements. ACI Structural Journal, 101, pp. 773-783. 
613 [32] ASCE (2017). Minimum Design Loads and Associated Criteria for Buildings and Other 614 Structures. ASCE/SEI 7-16. Reston, VA, USA. 